\title{
Reduced Plasma Nonesterified Fatty Acid Levels and the Advent of an Acute Lung Injury in Mice after Intravenous or Enteral Oleic Acid Administration
}

\author{
Cassiano Felippe Gonçalves de Albuquerque, ${ }^{1}$ Patrícia Burth, ${ }^{2}$ \\ Mauricio Younes Ibrahim, ${ }^{3}$ Diogo Gomes Garcia, ${ }^{1}$ Patrícia Torres Bozza, ${ }^{1}$ \\ Hugo Caire Castro Faria Neto, ${ }^{1}$ and Mauro Velho Castro Faria ${ }^{3}$ \\ ${ }^{1}$ Laboratório de Imunofarmacologia, Fundação Oswaldo Cruz, FIOCRUZ, Rio de Janeiro 21040-900, Brazil \\ ${ }^{2}$ Departamento de Biologia Celular e Molecular, Instituto de Biologia, Universidade Federal Fluminense, Niteroi 24020-150, Brazil \\ ${ }^{3}$ Departamento de Medicina Interna, Faculdade de Ciências Medicas, Universidade do Estado do Rio de Janeiro, \\ Rio de Janeiro 20550-900, Brazil
}

Correspondence should be addressed to Cassiano Felippe Gonçalves de Albuquerque, cassianofg@gmail.com

Received 26 September 2011; Revised 12 November 2011; Accepted 13 November 2011

Academic Editor: Giamila Fantuzzi

Copyright () 2012 Cassiano Felippe Gonçalves de Albuquerque et al. This is an open access article distributed under the Creative Commons Attribution License, which permits unrestricted use, distribution, and reproduction in any medium, provided the original work is properly cited.

\begin{abstract}
Although exerting valuable functions in living organisms, nonesterified fatty acids (NEFAs) can be toxic to cells. Increased blood concentration of oleic acid (OLA) and other fatty acids is detected in many pathological conditions. In sepsis and leptospirosis, high plasma levels of NEFA and low albumin concentrations are correlated to the disease severity. Surprisingly, $24 \mathrm{~h}$ after intravenous or intragastric administration of OLA, main NEFA levels (OLA inclusive) were dose dependently decreased. However, lung injury was detected in intravenously treated mice, and highest dose killed all mice. When administered by the enteral route, OLA was not toxic in any tested conditions. Results indicate that OLA has important regulatory properties on fatty acid metabolism, possibly lowering circulating fatty acid through activation of peroxisome proliferator-activated receptors. The significant reduction in blood NEFA levels detected after OLA enteral administration can contribute to the already known health benefits brought about by unsaturatedfatty-acid-enriched diets.
\end{abstract}

\section{Introduction}

Nonesterified fatty acids (NEFAs) are transported by the blood stream bound to albumin, a condition avoiding their cytotoxicity [1, 2]. Besides being an important fuel for the energetic metabolism, they also modulate leukocyte function, acting as signaling molecules [3-5]. Several cell types exhibit morphological features of apoptosis and necrosis after NEFA exposure [6,7]. Oleic (OLA) and linoleic acids activate caspases 3 and 6, enhancing the generation of reactive oxygen species and a significant mitochondrial depolarization in leukocytes $[8,9]$.

Symptom severity in diseases as sepsis, leptospirosis, and pancreatitis is associated to increased serum NEFA [1013]. Severe leptospirosis and sepsis are also characterized by a concomitant decrease in plasma albumin concentration consequent to a functional liver injury or increased vascular permeability possibly caused by NEFA toxicity [13-15]. Accordingly, increased OLA and decreased albumin plasma levels seem to predict the development of acute respiratory distress syndrome (ARDS) $[16,17]$. Since OLA and other nonesterified unsaturated fatty acids are potent $\mathrm{Na} / \mathrm{K}$-ATPase inhibitors, whether in vitro $[18,19]$ or in vivo $[20]$, the involvement of the lung $\mathrm{Na} / \mathrm{K}$ pump inhibition in the advent of ARDS has to be considered. In experimental animals, intravenous OLA injection can induce acute lung injury (ALI) $[21,22]$. This syndrome is characterized by neutrophil infiltration and edema formation [23], due to increased endothelial permeability and loss of epithelial barrier function [24], causing neutrophil and macrophage accumulation 
in the lung. Upon activation, these cells produce inflammatory mediators [25]. Lipid bodies (lipid-rich inclusions found in the leukocyte cytosol) are also augmented in ALI [26]. They act as amplifiers of inflammatory lipid mediator production such as prostaglandin $\mathrm{E}_{2}\left(\mathrm{PGE}_{2}\right)$ in macrophages and leukotriene $\mathrm{B}_{4}\left(\mathrm{LTB}_{4}\right)$ in macrophages and neutrophils [27]. In the present work, such parameters were used to characterize the onset of ALI after intravenous oleic acid administration.

On the other hand, many reports highlight the association of unsaturated fatty acid diets to a healthy lifestyle. The well-known Mediterranean diet contains large amounts of olive oil, which is rich in the esterified form of OLA [28]. Furthermore, dietary monounsaturated fatty acids were considered protective against metabolic syndrome and cardiovascular disease risks [29]. Populations using such diets have reduced serum triglycerides and lower incidence of cardiovascular problems [30,31].

The present study aimed at a better understanding of some deleterious and putative beneficial effects of OLA, when directly administered to mice. We investigated the consequences of increasing OLA doses, administered by intravenous or intragastric routes, on plasma NEFA concentration and on the triggering of an acute lung injury.

\section{Material and Methods}

2.1. Animals. All experiments were conducted on male Swiss mice weighting $33 \pm 3 \mathrm{~g}$ obtained from the Oswaldo Cruz Foundation breeding unit. Animals were lodged at $22^{\circ} \mathrm{C}$ with a $12 \mathrm{~h} \mathrm{light/dark}$ cycle and free access to food and water. Animal housing conditions and all experimental procedures conformed to institutional regulations and were in accordance with the National Institute of Health guidelines on animal care. All procedures described here were approved by the Institutional Animal Welfare Committee under license number 002-08.

2.2. Preparation of Tris-Oleate Solutions. Oleic acid obtained from Sigma Chemicals was used to prepare a $100 \mathrm{mmol} / \mathrm{L}$ tris-oleate solution. After weighting and water addition, tris powder (Trisma base-Sigma) was slowly added until the $\mathrm{pH}$ reached 10.0. The mixture was sonicated for complete trisoleate solubility and then the $\mathrm{pH}$ was carefully adjusted to 7.6 with diluted $\mathrm{HCl}$. Working oleate solutions were prepared by appropriate dilutions of the $100 \mathrm{mmol} / \mathrm{L}$ solution with phosphate buffered saline (PBS) pH 7.6.

2.3. Intravenous Administration of Oleate. Intravenous injections were performed into the orbital plexus (inner angle of the eye ball), and blood was collected by cardiac puncture $24 \mathrm{~h}$ latter. In some experiments, blood samples were collected 6 after the injection. Control groups received $100 \mu \mathrm{L}$ of saline. Other groups received $100 \mu \mathrm{L}$ of tris-oleate solutions corresponding to oleate doses of $20,40,80$, and $160 \mathrm{mg} / \mathrm{kg}$.

2.4. Intragastric Administration of Oleate. A thin catheter coupled to a $1.0 \mathrm{~mL}$ syringe was introduced through the mouse esophagus and $100 \mu \mathrm{L}$ of the appropriate oleate solution or PBS (control animals) were injected into the gastric lumen. Oleate doses of 20,40,80, and $160 \mathrm{mg} / \mathrm{kg}$ were also used. Blood was collected by cardiac puncture $24 \mathrm{~h}$ latter.

2.5. Plasma NEFA Quantification. Plasma concentrations of the predominant NEFA-palmitic, oleic, linoleic, palmitoleic, and stearic acids-were determined by high performance liquid chromatography (HPLC) as described by Puttman et al. [32]. Methodological details were delineated in a previous publication [13].

2.6. Albumin Quantification. Plasma albumin concentration was determined by the colorimetric procedure of Doumas et al. [33] using bovine serum albumin solutions as standards.

2.7. Total and Differential Cell Analysis on Bronchoalveolar Lavage Fluid (BALF). The bronchoalveolar lavage was performed after isolating the trachea by blunt dissection. A small caliber tube was inserted and secured in the airway. PBS $(1.0 \mathrm{~mL})$ was then instilled and gently aspirated. This procedure was repeated three times, and collected fluids were pooled. In every instillation/aspiration cycle, the same volume $(1.0 \mathrm{~mL})$ was recovered from each animal. Total leukocyte counts were performed by light microscopy in Neubauer chambers after diluting BALF samples in Türk's solution (2\% acetic acid). Differential leukocyte counts were determined in cytocentrifuged smears stained by the MayGrunwald-Giemsa method. Total BALF protein was determined by the Micron BCA Kit method (Pierce) according to the manufacturer's instructions.

2.8. Lipid Body Staining and Counting. While still moist, leukocytes on cytospin slides were fixed in $3.7 \%$ formaldehyde in $\mathrm{Ca}^{2+}, \mathrm{Mg}^{2+}$-free Hank's balanced salt solution (HBSS), pH 7.4 and stained with $1.5 \% \mathrm{OsO}_{4}$ as described in Bozza et al. [34]. Lipid bodies were counted by light microscopy with oil immersion objective lens in 50 consecutively scanned leukocytes.

2.9. $P G E_{2}$ and $\mathrm{LTB}_{4}$ Assays. $\mathrm{LTB}_{4}$ and $\mathrm{PGE}_{2}$ in BALF supernatants were assayed by ELISA kits according to the manufacturer's instructions (Cayman Chemical, Ann Arbor, MI).

2.10. Statistical Analysis. Results were expressed as mean \pm SEM and were analyzed by the Neuman-Keuls-Student test. Differences were considered significant when $P<0.05$.

\section{Results}

When mice were intravenously injected with increasing OLA doses $(20,40$ and $80 \mathrm{mg} / \mathrm{kg})$, a dose-dependent decrease in plasma NEFA concentrations especially oleic, linoleic and palmitic acids (Figure 1(a)), and total fatty acids (Figure 1(b)) were observed $24 \mathrm{~h}$ after the injection. To define if this effect could be detected at an earlier moment, we 


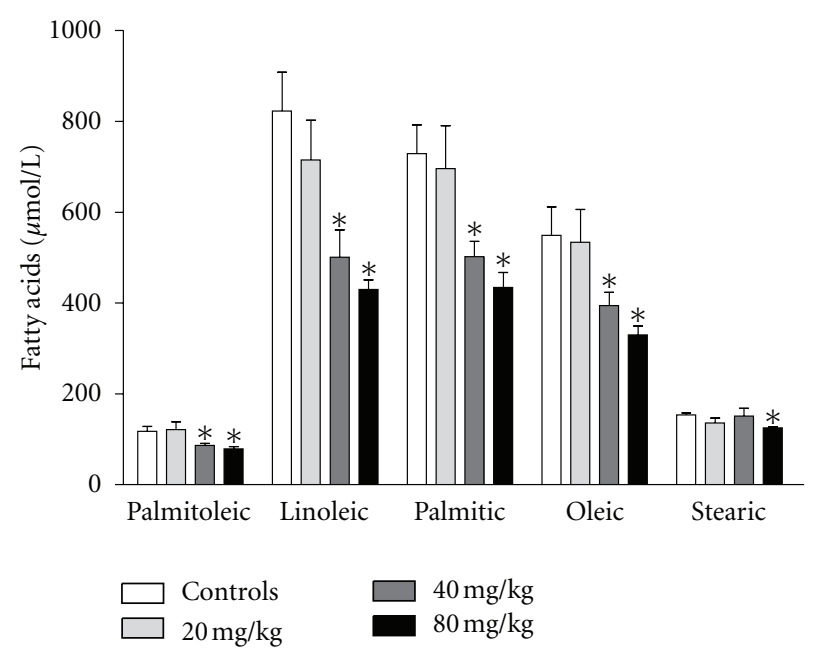

(a)

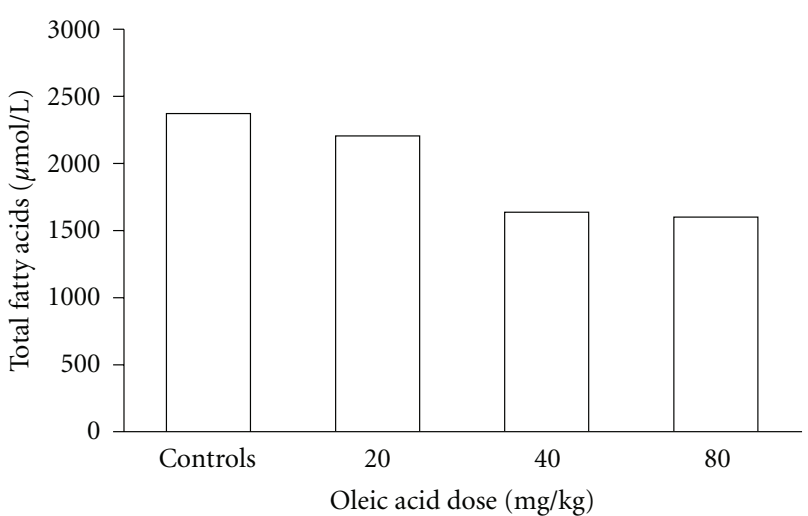

(b)

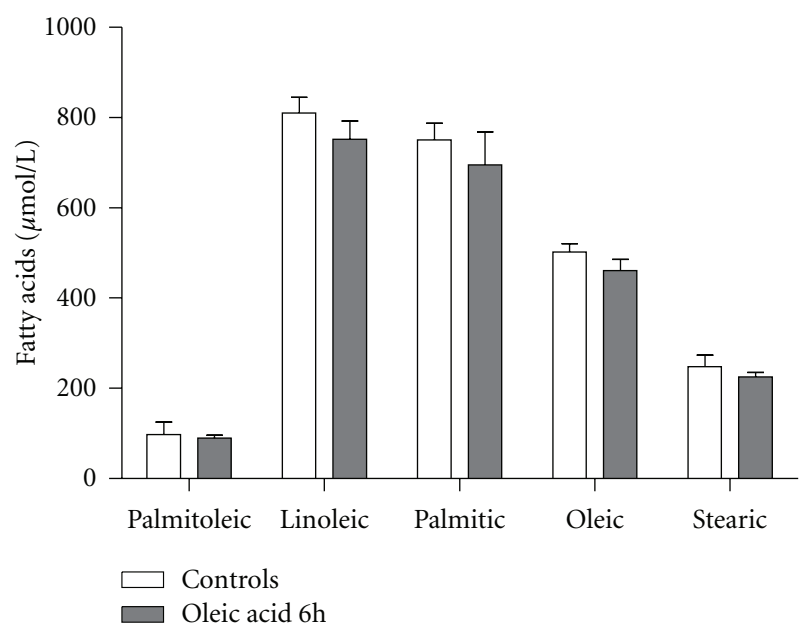

(c)

Figure 1: Plasma NEFA concentrations in mice after intravenous OLA injections. (a) Plasma concentrations of palmitoleic, linoleic, palmitic, oleic, and stearic acids $24 \mathrm{~h}$ after 20,40 , and $80 \mathrm{mg} / \mathrm{kg}$ oleic acid doses (mean \pm SEM of 5 different experiments). (b) Total NEFA concentration (sum of average concentrations of the five NEFA). All mice receiving the $160 \mathrm{mg} / \mathrm{kg}$ dose died 10-20 minutes after the intravenous injection and could not be computed. (c) Plasma concentrations of palmitoleic, linoleic, palmitic, oleic, and stearic acids $6 \mathrm{~h}$ after the injection of the $80 \mathrm{mg} / \mathrm{kg}$ oleic acid dose (mean \pm SEM of 4 independent experiments). ${ }^{*} P<0.05$ (versus controls).

TABLE 1: Plasma albumin concentrations $24 \mathrm{~h}$ after intravenous (I.V.) and intragastric (I.G.) OLA administration.

\begin{tabular}{lccccc}
\hline & & \multicolumn{4}{c}{ OLA dose $(\mathrm{mg} / \mathrm{kg})$} \\
& Controls & 20 & 40 & 30 & 160 \\
\hline Albumin $(\mu \mathrm{M})$ I.V. OLA & $357.2 \pm 8.1$ & $338.6 \pm 8.8$ & $325 \pm 20.0$ & $301.6 \pm 18.2$ & $\mathrm{nd}$ \\
Albumin $(\mu \mathrm{M})$ I.G. OLA & $367.3 \pm 12.1$ & $333.3 \pm 9.6$ & $326.4 \pm 19.1$ & $319.0 \pm 34.1$ & $350.1 \pm 19.4$ \\
\hline
\end{tabular}

Nd: not determined.

Results are mean \pm SEM of 6 to 7 different experiments.

performed an experiment evaluating NEFA concentrations $6 \mathrm{~h}$ after OLA injection, using the $80 \mathrm{mg} / \mathrm{kg}$ OLA dose (this dose corresponded to the maximal response obtained in the experiment of Figure 1(a)). Results for this early-time point (Figure 1(c)) showed only minor decreases relative to controls in some NEFA concentrations which were not statistically significant. Albumin levels were only slightly altered (Table 1).

In order to characterize the onset of ALI, we measured in BALF samples the following parameters: protein extravasation, leukocyte accumulation, lipid body formation in leukocytes and $\mathrm{PGE}_{2}$ and $\mathrm{LTB}_{4}$ production, which were 


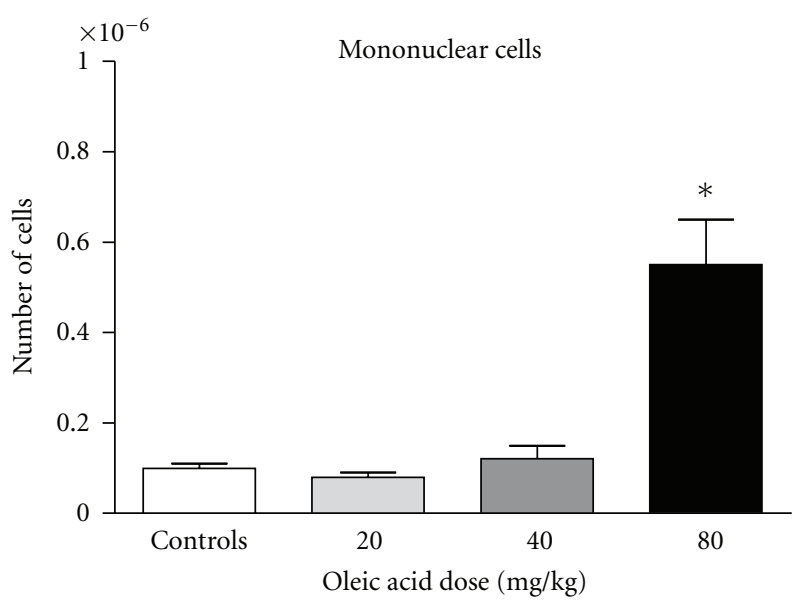

(a)

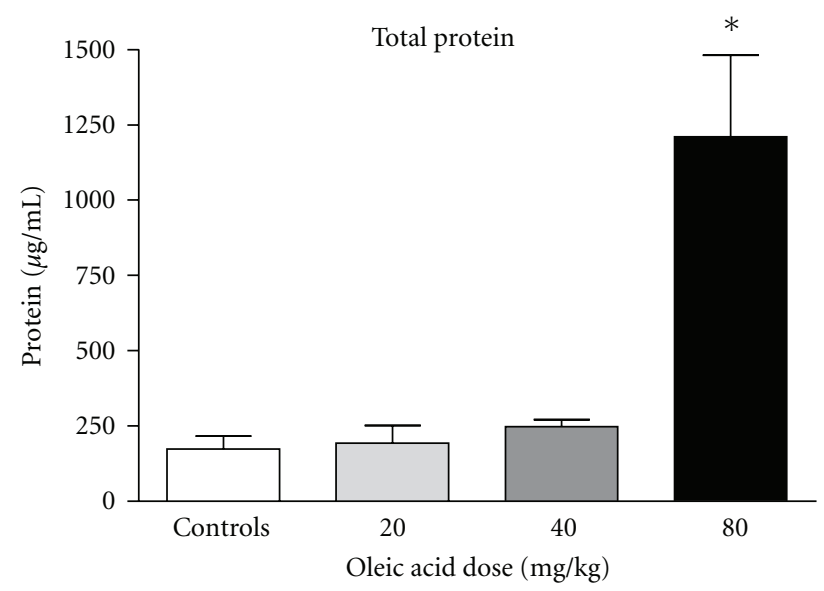

(c)

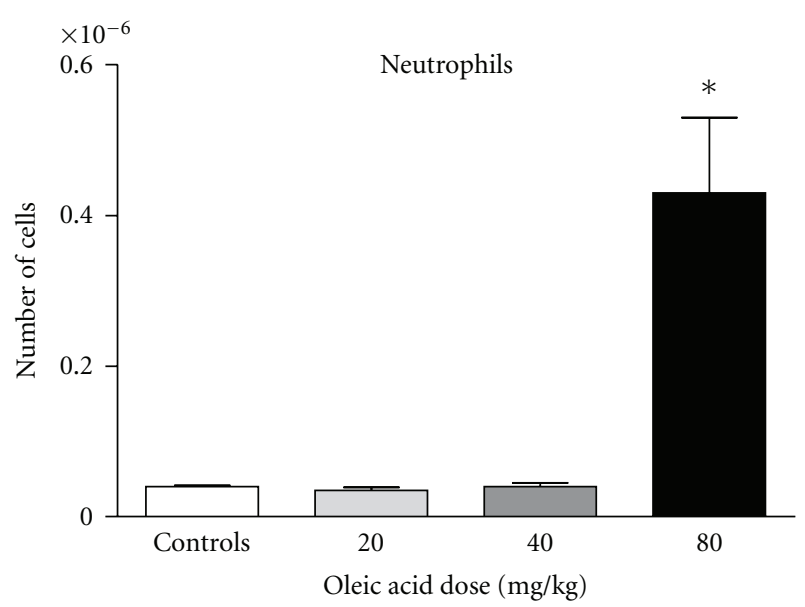

(b)

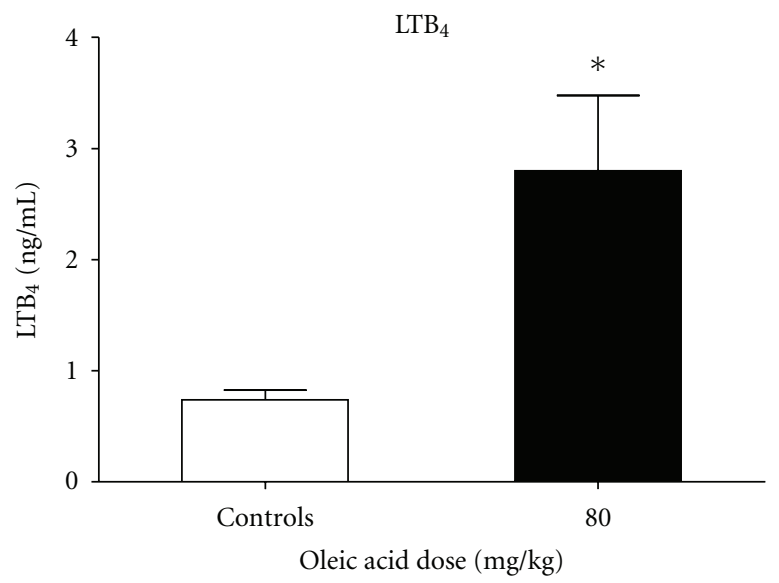

(d)

FIGURE 2: Leukocyte migration, protein extravasation, and $\mathrm{LTB}_{4}$ production in BALF after intravenous OLA injections. Mononuclear cells, neutrophils, and total protein (in BALF supernatants) were measured $24 \mathrm{~h}$ after injections, while $\mathrm{LTB}_{4}$ was assayed in supernatants $6 \mathrm{~h}$ after injections. Results represent the mean \pm SEM of 3 independent experiments. ${ }^{*} P<0.05$.

used as markers of lung edema and inflammation. Although OLA is potentially able to induce lung injury, intravenously injected OLA in 20 and $40 \mathrm{mg} / \mathrm{kg}$ doses did not induce BALF cell migration or did not produce modifications on protein BALF content (Figure 2). Notwithstanding, $24 \mathrm{~h}$ after the $80 \mathrm{mg} / \mathrm{kg}$ dose, an infiltration of mononuclear cells and neutrophils, as well as an augmented total BALF protein, was detected. $\mathrm{LTB}_{4}$ was also significantly increased $6 \mathrm{~h}$ after this challenge (Figure 2). Lipid bodies in BALF leukocytes and the lipid mediator $\mathrm{PGE}_{2}$ in BALF supernatant (Figure 3) were also considerably augmented $24 \mathrm{~h}$ after this same OLA challenge. A dose of $160 \mathrm{mg} / \mathrm{kg}$ killed all mice. These animals presented early signs of severe lung injury and died within 10 minutes after injections.

When the same OLA doses were administered to mice by the enteral route, lowered individual and total NEFA concentrations were also detected (Figures 4(a) and 4(b), resp.). This decrease was substantially more pronounced than the one seen in intravenously treated animals. Lung injury was not found even in the highest dose tested as can be seen in Figure 5. Since lung edema and leukocyte infiltration were not detected in this experiment, assays for inflammatory mediators were not performed.

\section{Discussion}

Herein we demonstrated an unexpected decrease in NEFA plasma levels after intravenous or enteral OLA administration. In this regard, several studies have shown that fatty acids can regulate its own metabolism, acting at gene transcription level. Some transcription factors are prospective fatty acid targets regulating the expression of enzymes involved in lipid metabolism [35-38]. Nonesterified fatty acid availability is sensed by peroxisome proliferatoractivated receptors (PPARs), which are nuclear receptors controlling fatty acid storage, degradation, and adipocyte differentiation $[39,40]$. Although in the present study we did not test OLA binding to PPAR, this fatty acid was already reported so effective as polyunsaturated fatty acids 


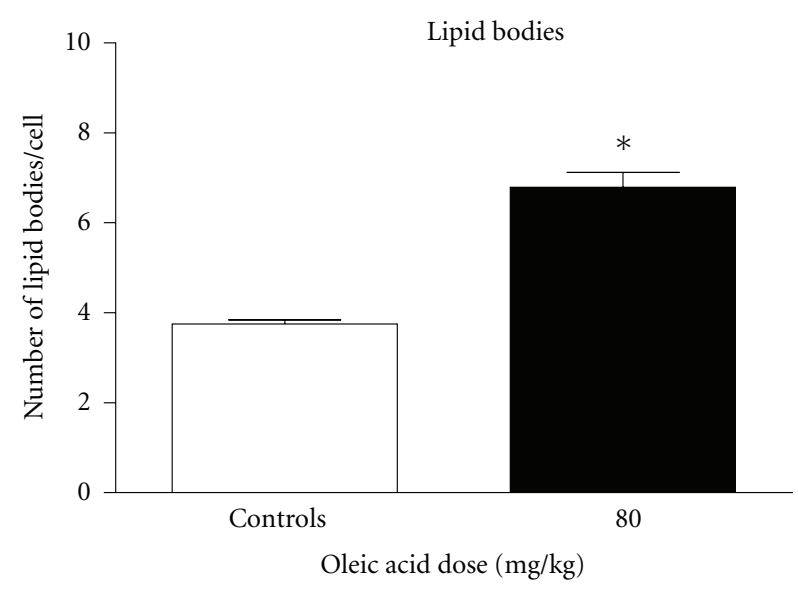

(a)

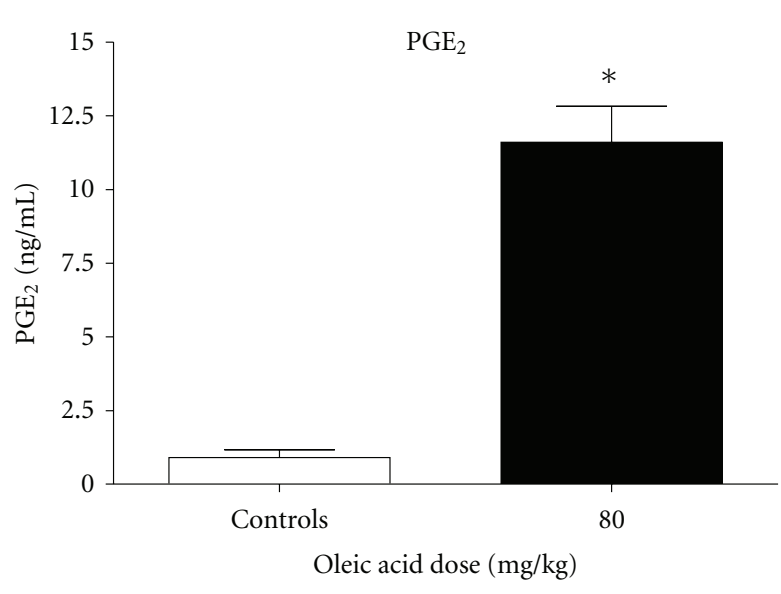

(b)

FIGURE 3: Lipid body formation and prostaglandin production in BALF after intravenous OLA injections. BALF were collected $24 \mathrm{~h}$ after injections of the $80 \mathrm{mg} / \mathrm{kg}$ dose. Each bar represents the mean \pm SEM of lipid bodies per cell in 50 consecutively counted cells from 6 different animals. $\mathrm{PGE}_{2}$ quantification is the mean \pm SEM of 3 independent experiments. ${ }^{*} P<0.05$.

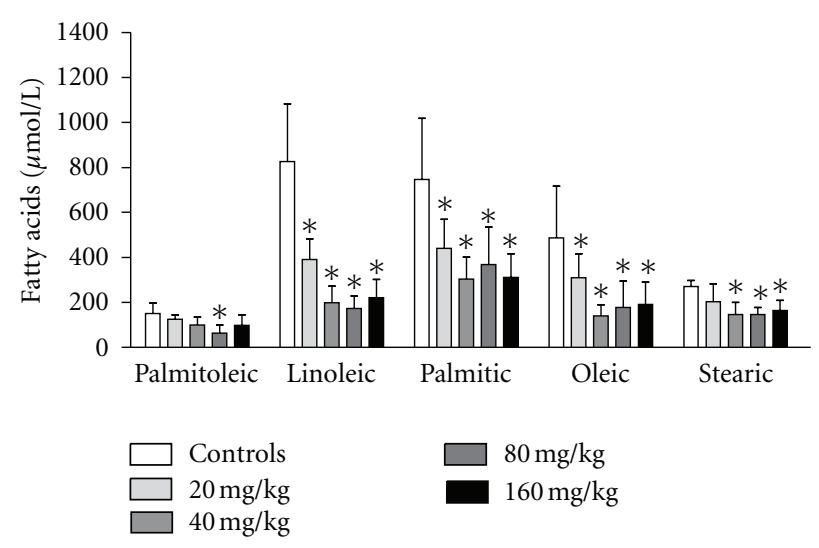

(a)

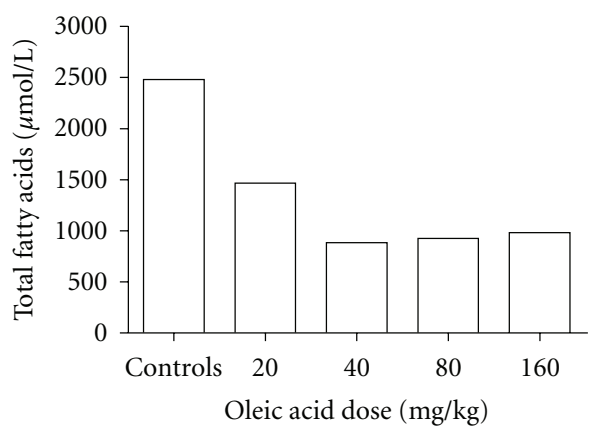

(b)

FIgURE 4: Plasma NEFA concentrations after OLA administration by the gastric route. (a) Plasma concentrations of palmitoleic, linoleic, palmitic, oleic, and stearic acids $24 \mathrm{~h}$ after 20,40, 80, and $160 \mathrm{mg} / \mathrm{kg}$ oleic acid doses; (b) total NEFA concentration (sum of average concentrations of the five NEFA). Results represent data from 5 independent experiments (mean \pm SEM). ${ }^{*} P<0.05$.

in PPAR $\alpha$ binding and activation [41] and was also a PPAR $\gamma$ ligand [42]. In fact, PPAR $\alpha$ activation in the liver stimulates the transcription of carnitine palmitoil-transferase 1 (CPT1) and uncoupling protein 1 , leading to increased fatty acid degradation [43]. Fish oils contain PPAR $\alpha$ activators that, similarly to hypolipidemic drugs, decreased triglyceride synthesis and increased mitochondrial fatty acid $\beta$-oxidation [44]. PPAR $y$ activation augmented fatty acid clearance by the adipose tissue and hepatocytes, consequently decreasing their plasma concentrations [45]. Hence, PPAR activation seems to be an important condition decreasing nonesterified fatty acid blood concentrations. In this way, PPAR $\gamma$ agonists lowered plasmatic NEFA concentration [45] while PPAR $\alpha$ agonists led to a similar effect by increasing NEFA oxidation [46].
Mice receiving OLA through the intravenous route $(80 \mathrm{mg} / \mathrm{kg})$ already presented signals of lung injury, characterized by increased protein extravasation, cell migration and cell activation with increased lipid body formation and $\mathrm{PGE}_{2}$ release. Moreover, $\mathrm{LTB}_{4}$, a potent neutrophil chemotactic molecule [47], was augmented at an early stage, thus contributing for neutrophil migration. In our conditions, OLA lung toxicity can be explained by the rapid arrival of albumin unbound-OLA in the lung capillary net. It is important to note that this amount of OLA, if diluted in the whole mouse blood (considered as $2.5 \mathrm{~mL}$ ), would give a concentration of at least $4000 \mu \mathrm{mol} / \mathrm{L}$, which is around 1.7 and 6.6 times the control levels of total fatty acid and OLA, respectively. Surely, during the few seconds of traveling from the injection point to lung, OLA concentration would be much higher than $4000 \mu \mathrm{mol} / \mathrm{L}$. 


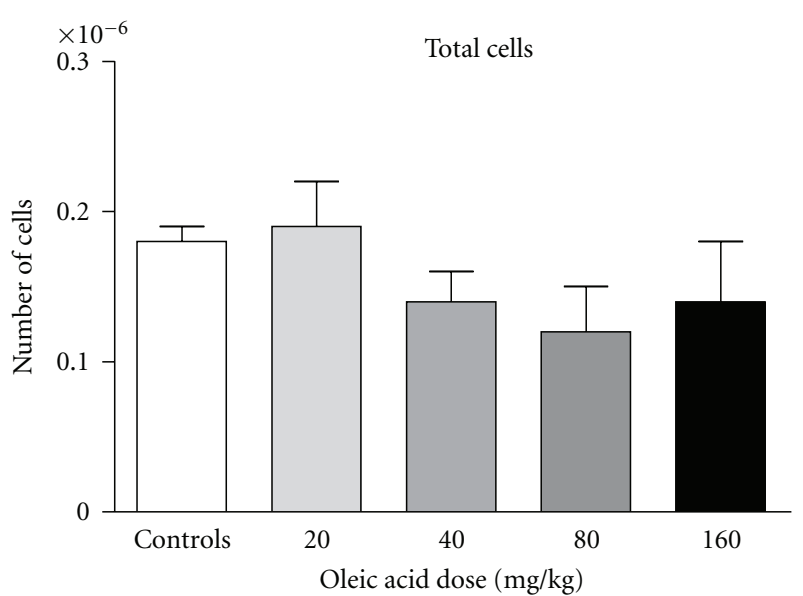

(a)

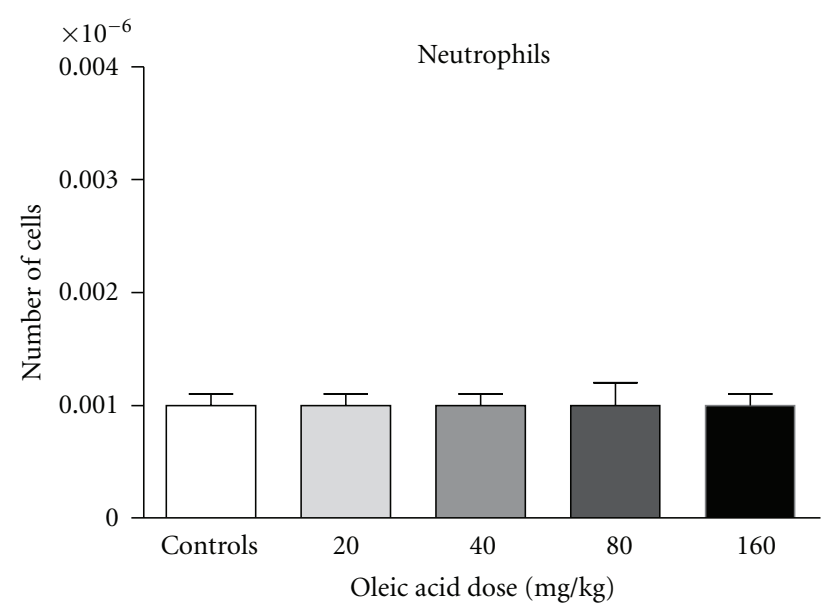

(c)

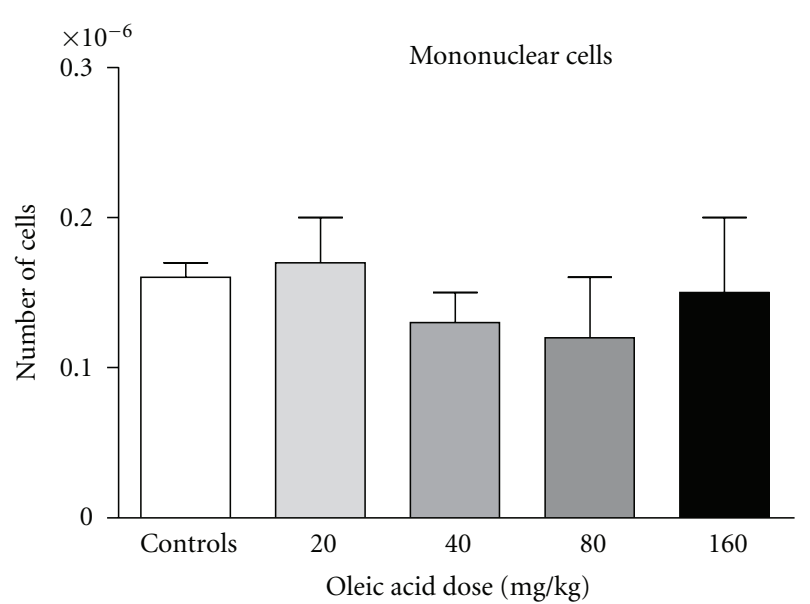

(b)

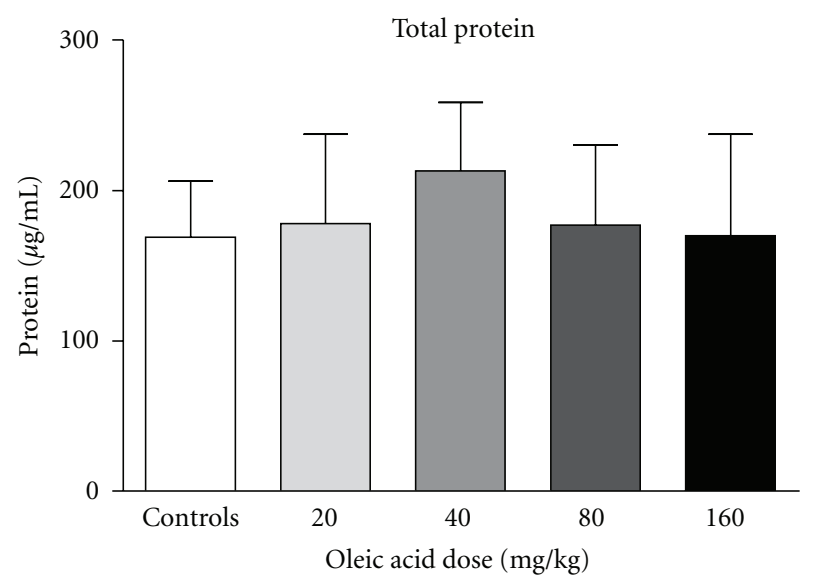

(d)

FIGURE 5: Leukocyte migration and protein extravasation in BALF after OLA administration by the gastric route. Bronchoalveolar fluids were collected $24 \mathrm{~h}$ after OLA administration. Total cells, mononuclear cells, and neutrophils were counted. Total protein in BALF supernatants was also assayed. Results represent the mean \pm SEM of 3 independent experiments.

Moreover, a $160 \mathrm{mg} / \mathrm{kg}$ intravenous dose killed all animals within $10 \mathrm{~min}$ after injections, a toxic effect certainly due to albumin unbound-OLA. In this context, it was proposed that the toxicity of intravenously administered OLA could be diminished by a concomitant albumin injection [48].

OLA enteral administration was not toxic in any tested doses. Since an appreciable part of OLA undergoes esterification during the intestinal absorptive mechanism and considering that intestinal absorption is a much slower process, an increase in albumin unbound-OLA is prevented in this condition. It is worth of note that OLA administration by the gastric route $(40-80 \mathrm{mg} / \mathrm{kg})$ was twice as much efficient in lowering total plasma NEFA (a decrease of about 60\%) than the intravenous administration (around $30 \%$ ). At this point, we would like to emphasize published data showing that mice consuming olive oil-enriched diet (thus an OLA enriched-diet) had increased survival after a LPS induced-shock [49]. This shock is characteristically seen in sepsis, a disease coursing with high plasma NEFA concentrations. In this case, diet-induced-reduced-plasma NEFA could be an explanation for the extended mice survival.

There are evident differences in OLA distribution in the body when this fatty acid is administered by intravenous or enteral routes. In intravenously treated animals, OLA is rapidly and significantly trapped in the lung microvasculature causing lung inflammation. After enteral administration, OLA is mostly esterified and transported through the abdominal lymphatic system then reaching the venous system, heart, lung and, afterwards, is distributed to the whole organism. The enteral route follows, thus, the normal physiologic mechanisms of lipid absorption and transport.

Other nonesterified fatty acids may have similar effects on NEFA plasma levels. In this work, OLA was chosen because not only toxic but also benefic effects of this fatty acid are well documented in the literature. 


\section{Conclusions}

In conclusion, OLA seems to participate in the regulation of fatty acid metabolism. Intravenous OLA administration (40 mg per kg of body weight) lowered plasma NEFA concentrations, but higher doses were toxic, leading to lung injury or killing the animals. On the other side, our results suggest a benefic effect of low doses of orally administered OLA (about 40 to $80 \mathrm{mg}$ per kg of body weight) in reducing plasma NEFA concentrations of normal animals. This finding sum up the other benefits brought about by the ingestion of diets containing OLA-enriched fat, particularly olive oil.

\section{Abbreviations}

ALI: Acute lung injury

ARDS: Acute respiratory distress syndrome

BALF: Bronchoalveolar lavage fluid

CPT1: Carnitine palmitoil-transferase 1

NEFA: Nonesterified fatty acids

HPLC: High performance liquid chromatography

IL: Interleukin

$\mathrm{LTB}_{4}$ : Leukotriene $\mathrm{B}_{4}$

IV: Intravenous

IG: Intragastric

LNA: Linoleic acid $(18: 2 \mathrm{n}-6)$

OLA: Oleic acid (18:1n-9)

$\mathrm{PGE}_{2}$ : Prostaglandin $\mathrm{E}_{2}$

PPAR: Peroxisome proliferator-activated receptors

TNF: Tumor necrosis factor.

\section{Acknowledgments}

This work received financial supports from Fundação de Amparo a Pesquisa do Estado do Rio de Janeiro (FAPERJ), Grants E-26/111.636/2008 and E-26/111.024/2008, Programa Estratégico de Apoio à Pesquisa em Saúde (PAPES) FIOCRUZ, and Conselho Nacional de Desenvolvimento Científico e Tecnológico (CNPq). The authors acknowledge the following institutions where this work was accomplished: Universidade do Estado do Rio de Janeiro (UERJ), Fundação Oswaldo Cruz (FIOCRUZ) e Universidade Federal Fluminense (UFF). They thank Dr. Emely Kazan for the skilled help in performing the chromatographic work.

\section{References}

[1] G. J. van der Vusse, "Albumin as fatty acid transporter," Drug Metabolism and Pharmacokinetics, vol. 24, no. 4, pp. 300-307, 2009.

[2] J. M. Weinberg, "Lipotoxicity," Kidney International, vol. 70, no. 9, pp. 1560-1566, 2006.

[3] T. Martins De Lima, R. Gorjão, E. Hatanaka et al., "Mechanisms by which fatty acids regulate leucocyte function," Clinical Science, vol. 113, no. 1-2, pp. 65-77, 2007.

[4] S. Costanzi, S. Neumann, and M. C. Gershengorn, "Seven transmembrane-spanning receptors for free fatty acids as therapeutic targets for diabetes mellitus: pharmacological, phylogenetic, and drug discovery aspects," Journal of Biological Chemistry, vol. 283, no. 24, pp. 16269-16273, 2008.
[5] P. Yaqoob and P. C. Calder, "Fatty acids and immune function: new insights into mechanisms," British Journal of Nutrition, vol. 98, no. 1, pp. S41-S45, 2007.

[6] M. Artwohl, A. Lindenmair, M. Roden et al., "Fatty acids induce apoptosis in human smooth muscle cells depending on chain length, saturation, and duration of exposure," Atherosclerosis, vol. 202, no. 2, pp. 351-362, 2009.

[7] P. Rockenfeller, J. Ring, V. Muschett et al., "Fatty acids trigger mitochondrion-dependent necrosis," Cell Cycle, vol. 9, no. 14, pp. 2836-2842, 2010.

[8] D. A. Healy, R. W. G. Watson, and P. Newsholme, "Polyunsaturated and monounsaturated fatty acids increase neutral lipid accumulation, caspase activation and apoptosis in a neutrophil-like, differentiated hl-60 cell line," Clinical Science, vol. 104, no. 2, pp. 171-179, 2003.

[9] T. Martins De Lima, M. F. Cury-Boaventura, G. Giannocco, M. T. Nunes, and R. Curi, "Comparative toxicity of fatty acids on a macrophage cell line (J774)," Clinical Science, vol. 111, no. 5, pp. 307-317, 2006.

[10] H. R. Rosen and H. Tuchler, "Pulmonary injury in acute experimental pancreatitis correlates with elevated levels of free fatty acids in rats," HPB Surgery, vol. 6, no. 2, pp. 79-90, 1992.

[11] K. Sztefko and J. Panek, "Serum free fatty acid concentration in patients with acute pancreatitis," Pancreatology, vol. 1, no. 3, pp. 230-236, 2001.

[12] A. C. Nogueira, V. Kawabata, P. Biselli et al., "Changes in plasma free fatty acid levels in septic patients are associated with cardiac damage and reduction in heart rate variability," Shock, vol. 29, no. 3, pp. 342-348, 2008.

[13] P. Burth, M. Younes-Ibrahim, M. C. B. Santos, H. C. CastroFaria Neto, and M. V. De Castro Faria, "Role of nonesterified unsaturated fatty acids in the pathophysiological processes of leptospiral infection," Journal of Infectious Diseases, vol. 191, no. 1, pp. 51-57, 2005.

[14] A. Fleck, G. Raines, and F. Hawker, "Increased vascular permeability: a major cause of hypoalbuminaemia in disease and injury," The Lancet, vol. 1, no. 8432, pp. 781-784, 1985.

[15] B. Ruot, D. Breuillé, F. Rambourdin, G. Bayle, P. Capitan, and C. Obled, "Synthesis rate of plasma albumin is a good indicator of liver albumin synthesis in sepsis," American Journal of Physiology, vol. 279, no. 2, pp. E244-E251, 2000.

[16] A. T. Hostmark, "Serum fatty acid/albumin molar ratio and the risk of diseases," Medical Hypotheses, vol. 44, no. 6, pp. 539-541, 1995.

[17] S. L. Bursten, D. A. Federighi, P. E. Parsons et al., "An increase in serum $\mathrm{C} 18$ unsaturated free fatty acids as a predictor of the development of acute respiratory distress syndrome," Critical Care Medicine, vol. 24, no. 7, pp. 1129-1136, 1996.

[18] M. Younes-Ibrahim, P. Burth, M. V. Castro Faria et al., "Inhibition of $\mathrm{Na}, \mathrm{K}$-ATPase by an endotoxin extracted from Leptospira interrogans: a possible mechanism for the physiopathology of leptospirosis," Comptes Rendus de l'Academie des Sciences, vol. 318, no. 5, pp. 619-625, 1995.

[19] M. Younes-Ibrahim, B. Buffin-Meyer, L. Cheval et al., "Na,KATPase: a molecular target for Leptospira interrogans endotoxin," Brazilian Journal of Medical and Biological Research, vol. 30, no. 2, pp. 213-223, 1997.

[20] I. Vadász, R. E. Morty, A. Olschewski et al., “Thrombin impairs alveolar fluid clearance by promoting endocytosis of $\mathrm{Na}^{+}, \mathrm{K}^{+}$ATPase," American Journal of Respiratory Cell and Molecular Biology, vol. 33, no. 4, pp. 343-354, 2005.

[21] K. G. Davidson, A. D. Bersten, H. A. Barr, K. D. Dowling, T. E. Nicholas, and I. R. Doyle, "Lung function, permeability, and surfactant composition in oleic acid-induced acute lung 
injury in rats," American Journal of Physiology, vol. 279, no. 6, pp. L1091-L1102, 2000.

[22] G. Beilman, "Pathogenesis of oleic acid-induced lung injury in the rat: distribution of oleic acid during injury and early endothelial cell changes," Lipids, vol. 30, no. 9, pp. 817-823, 1995.

[23] C. L. Guimarães, P. G. Trentin, and G. A. Rae, "Endothelin ETB receptor-mediated mechanisms involved in oleic acidinduced acute lung injury in mice," Clinical Science, vol. 103, supplement 48, pp. 340S-344S, 2002.

[24] L. B. Ware and M. A. Matthay, "The acute respiratory distress syndrome," New England Journal of Medicine, vol. 342, no. 18, pp. 1334-1349, 2000.

[25] M. A. Matthay and G. A. Zimmerman, "Acute lung injury and the acute respiratory distress syndrome: four decades of inquiry into pathogenesis and rational management," American Journal of Respiratory Cell and Molecular Biology, vol. 33, no. 4, pp. 319-327, 2005.

[26] P. T. Bozza, K. G. Magalhães, and P. F. Weller, "Leukocyte lipid bodies-Biogenesis and functions in inflammation," Biochimica et Biophysica Acta, vol. 1791, no. 6, pp. 540-551, 2009.

[27] P. T. Bozza and J. P. B. Viola, "Lipid droplets in inflammation and cancer," Prostaglandins Leukotrienes and Essential Fatty Acids, vol. 82, no. 4-6, pp. 243-250, 2010.

[28] P. M. Kris-Etherton, "AHA science advisory. monounsaturated fatty acids and risk of cardiovascular disease. American Heart Association. Nutrition Committee," Circulation, vol. 100, no. 11, pp. 1253-1258, 1999.

[29] L. G. Gillingham, S. Harris-Janz, and P. J. H. Jones, "Dietary monounsaturated fatty acids are protective against metabolic syndrome and cardiovascular disease risk factors," Lipids, vol. 46, no. 3, pp. 209-228, 2011.

[30] W. C. Willett, F. Sacks, A. Trichopoulou et al., "Mediterranean diet pyramid: a cultural model for healthy eating," American Journal of Clinical Nutrition, vol. 61, no. 6, pp. 3277-3288, 1995.

[31] D. Richard, P. Bausero, C. Schneider, and F. Visioli, "Polyunsaturated fatty acids and cardiovascular disease," Cellular and Molecular Life Sciences, vol. 66, no. 20, pp. 3277-3288, 2009.

[32] M. Puttmann, H. Krug, E. Von Ochsenstein, and R. Kattermann, "Fast HPLC determination of serum free fatty acids in the picomole range," Clinical Chemistry, vol. 39, no. 5, pp. 825-832, 1993.

[33] B. T. Doumas, W. Ard Watson, and H. G. Biggs, "Albumin standards and the measurement of serum albumin with bromcresol green," Clinica Chimica Acta, vol. 31, no. 1, pp. 8796, 1971.

[34] P. T. Bozza, J. L. Payne, S. G. Morham, R. Langenbach, O. Smithies, and P. F. Weller, "Leukocyte lipid body formation and eicosanoid generation: cyclooxygenase-independent inhibition by aspirin," Proceedings of the National Academy of Sciences of the United States of America, vol. 93, no. 20, pp. 11091-11096, 1996.

[35] H. Sampath and J. M. Ntambi, "Polyunsaturated fatty acid regulation of genes of lipid metabolism," Annual Review of Nutrition, vol. 25, pp. 317-340, 2005.

[36] D. B. Jump, D. Botolin, Y. Wang, J. Xu, B. Christian, and O. Demeure, "Fatty acid regulation of hepatic gene transcription," Journal of Nutrition, vol. 135, no. 11, pp. 25032506, 2005.

[37] R. Verlengia, R. Gorjão, C. C. Kanunfre et al., "Genes regulated by arachidonic and oleic acids in raji cells," Lipids, vol. 38, no. 11, pp. 1157-1165, 2003.
[38] D. B. Jump, S. D. Clarke, A. Thelen, and M. Liimatta, "Coordinate regulation of glycolytic and lipogenic gene expression by polyunsaturated fatty acids," Journal of Lipid Research, vol. 35, no. 6, pp. 1076-1084, 1994.

[39] M. P. Wymann and R. Schneiter, "Lipid signalling in disease," Nature Reviews Molecular Cell Biology, vol. 9, no. 2, pp. 162176, 2008.

[40] M. C. Cho, K. Lee, S. G. Paik, and D. Y. Yoon, "Peroxisome proliferators-activated receptor (PPAR) modulators and metabolic disorders," PPAR Research, vol. 2008, Article ID 679137, 14 pages, 2008.

[41] H. E. Xu, M. H. Lambert, V. G. Montana et al., "Molecular recognition of fatty acids by peroxisome proliferator- activated receptors," Molecular Cell, vol. 3, no. 3, pp. 397-403, 1999.

[42] B. Desvergne and W. Wahli, "Peroxisome proliferatoractivated receptors: nuclear control of metabolism," Endocrine Reviews, vol. 20, no. 5, pp. 649-688, 1999.

[43] T. C. Leone, C. J. Weinheimer, and D. P. Kelly, "A critical role for the peroxisome proliferator-activated receptor $\alpha(\operatorname{PPAR} \alpha)$ in the cellular fasting response: the PPAR $\alpha$-null mouse as a model of fatty acid oxidation disorders," Proceedings of the National Academy of Sciences of the United States of America, vol. 96, no. 13, pp. 7473-7478, 1999.

[44] R. K. Berge, L. Madsen, H. Vaagenes, K. J. Tronstad, M. Göttlicher, and A. C. Rustan, "In contrast with docosahexaenoic acid, eicosapentaenoic acid and hypolipidaemic derivatives decrease hepatic synthesis and secretion of triacylglycerol by decreased diacylglycerol acyltransferase activity and stimulation of fatty acid oxidation," Biochemical Journal, vol. 343, no. 1, pp. 191-197, 1999.

[45] N. D. Oakes, S. Camilleri, S. M. Furler, D. J. Chisholm, and E. W. Kraegen, “The insulin sensitizer, BRL 49653, reduces systemic fatty acid supply and utilization and tissue lipid availability in the rat," Metabolism, vol. 46, no. 8, pp. 935-942, 1997.

[46] D. M. Muoio, J. M. Way, C. J. Tanner et al., "Peroxisome proliferator-activated receptor- $\alpha$ regulates fatty acid utilization in primary human skeletal muscle cells," Diabetes, vol. 51, no. 4, pp. 901-909, 2002.

[47] B. Samuelsson, S. E. Dahlen, and J. A. Lindgren, "Leukotrienes and lipoxins: structures, biosynthesis, and biological effects," Science, vol. 237, no. 4819, pp. 1171-1176, 1987.

[48] A. Bezman-Tarcher, "Method for continuous intravenous infusion of large amounts of oleic acid into rats," Journal of Lipid Research, vol. 10, no. 2, pp. 197-206, 1969.

[49] M. S. Leite, P. Pacheco, R. N. Gomes et al., "Mechanisms of increased survival after lipopolysaccharide-induced endotoxic shock in mice consuming olive oil-enriched diet," Shock, vol. 23, no. 2, pp. 173-178, 2005. 


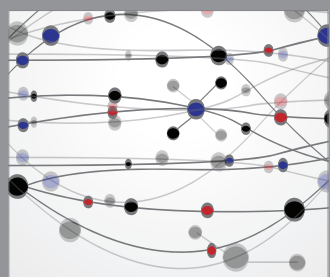

The Scientific World Journal
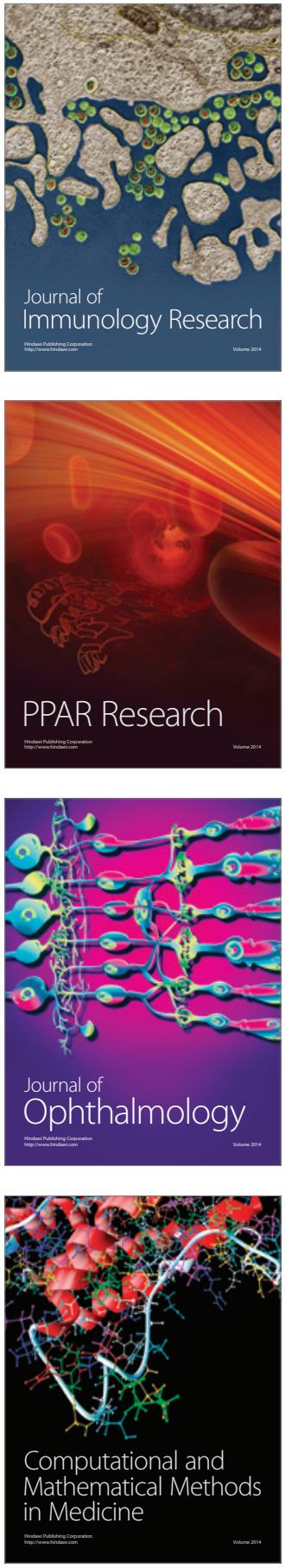

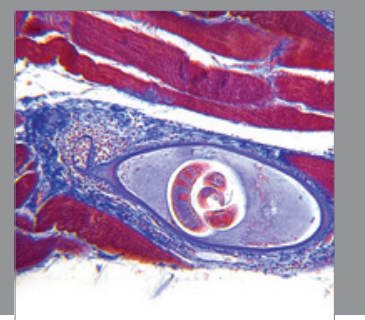

Gastroenterology

Research and Practice
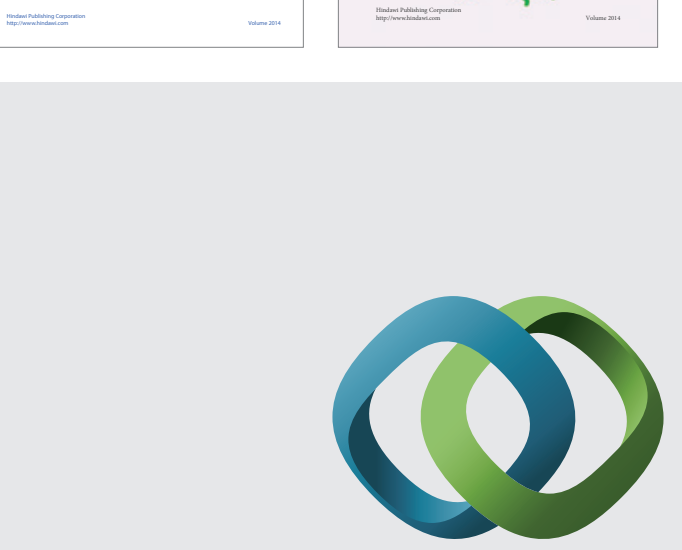

\section{Hindawi}

Submit your manuscripts at

http://www.hindawi.com
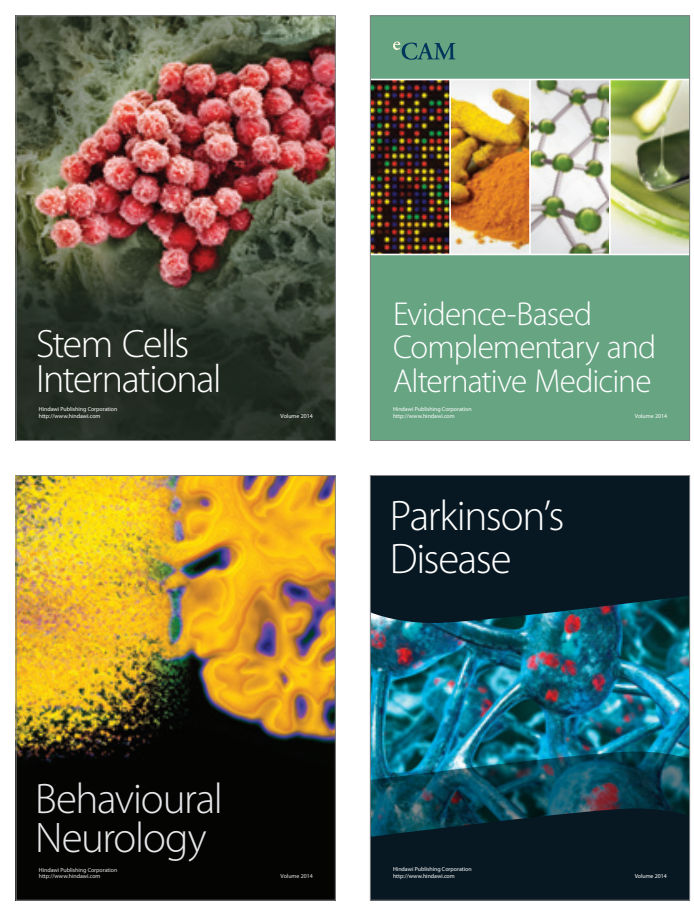

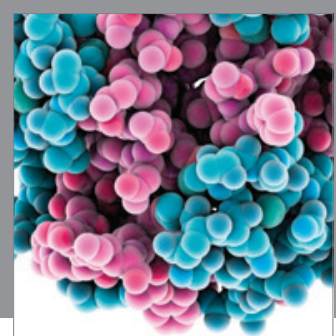

Journal of
Diabetes Research

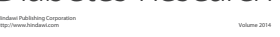

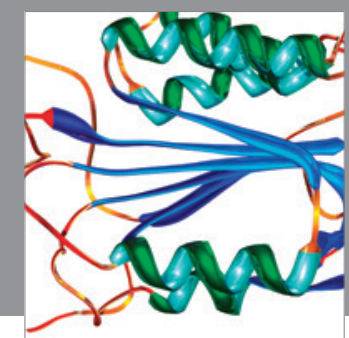

Disease Markers
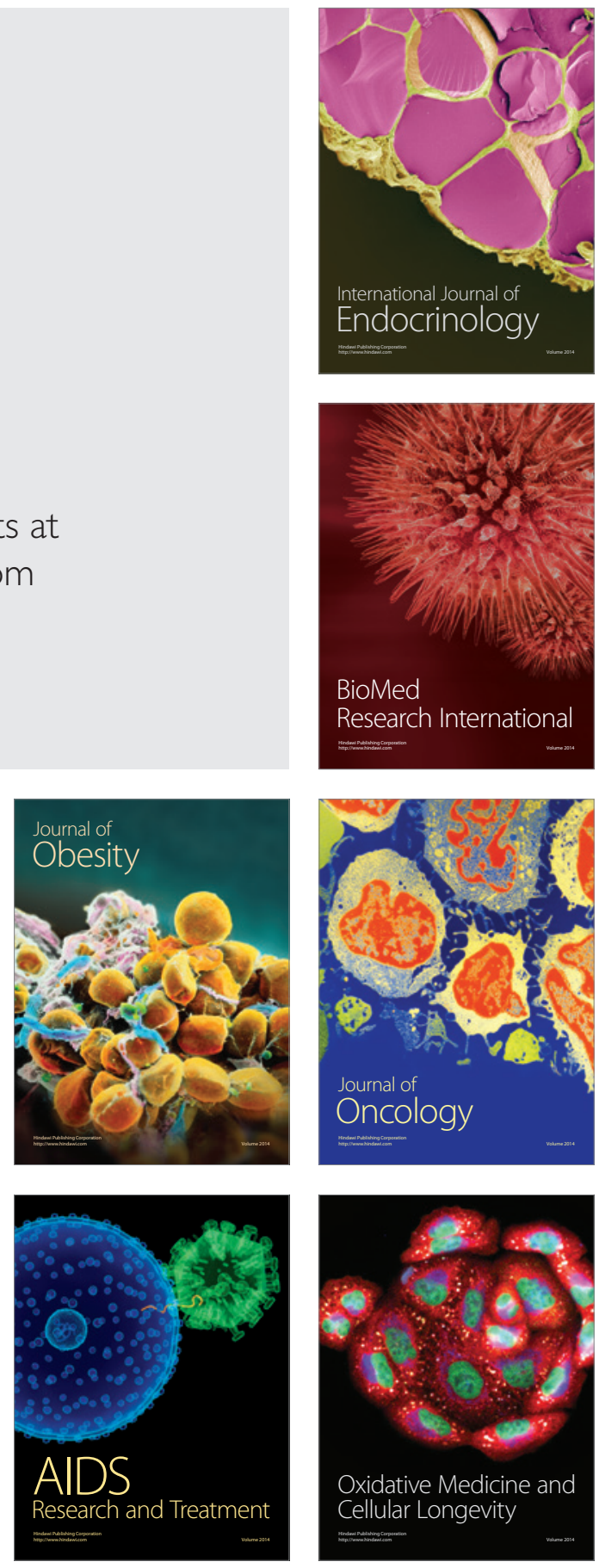